\title{
Atrial Natriuretic Peptides Inhibit Conductive Sodium Uptake by Rabbit Inner Medullary Collecting Duct Cells
}

\author{
Mark L. Zeidel, Deepak Kikeri, Patricio Silva, Mark Burrowes, and Barry M. Brenner \\ Renal Division and Department of Medicine, Brigham and Women's, Beth Israel, and Brocton-West Roxbury Veterans Administration \\ Hospitals, Harvard Center for the Study of Kidney Diseases, Harvard Medical School, Boston, Massachusetts 02115
}

\begin{abstract}
The inner medullary collecting duct (IMCD) effects net sodium reabsorption under the control of volume regulatory hormones, including atrial natriuretic peptides (ANP). These studies examined the mechanisms of sodium transport and its regulation by ANP in fresh suspensions of IMCD cells. Sodium uptake was inhibited by amiloride but insensitive to furosemide, bumetanide, and hydrochlorthiazide. These results are consistent with uptake mediated by a sodium channel or $\mathrm{Na}^{+} / \mathrm{H}^{+}$exchange. To determine the role of sodium channels, cells were hyperpolarized by preincubation in high potassium medium followed by dilution into potassium-free medium. Membrane potential measurements using the cyanine dye, $\mathrm{Di}(\mathrm{S})-\mathrm{C}_{3}-5$ verified a striking hyperpolarization of IMCD cells using this protocol. Hyperpolarization increased the apparent initial rate of sodium uptake fourfold. Amiloride and ANP inhibited potential-stimulated sodium uptake $73 \%$ and $65 \%$, respectively; the two agents together were not additive. Addition of $5 \mathrm{mM}$ sodium to hyperpolarized cells resulted in a significant amiloride-sensitive depolarization. Half-maximal inhibition of potential-driven sodium uptake occurred at $3 \times 10^{-7} \mathrm{M}$ amiloride, and $5 \times 10^{-11} \mathrm{M}$ ANP. We conclude that sodium enters IMCD cells via a conductive, amiloride-sensitive sodium channel, which is regulated by ANP. ANP inhibition of luminal sodium entry in the IMCD appears to contribute to the marked natriuretic effect of this hormone in vivo.
\end{abstract}

\section{Introduction}

Under normal conditions, the inner medullary collecting duct $(\mathrm{IMCD})^{1}$ reabsorbs $\sim 2 \%$ of the glomerular filtrate (1). Although little is known about the mechanisms of sodium reabsorption in this segment, micropuncture, microcatheterization, and in vitro microperfusion studies have shown that sodium reabsorption is active, and stimulated in vivo by aldosterone (1-4). By analogy with sodium handling in more proximal segments, a luminal sodium entry mechanism might

Address reprint requests to Dr. Zeidel, Laboratory of Kidney and Electrolyte Physiology, Brigham and Women's Hospital, 75 Francis Street, Boston, MA 02115.

Received for publication 11 November 1987 and in revised form 16 March 1988.

1. Abbreviations used in this paper: ANP, atrial natriuretic peptide(s); IMCD, inner medullary collecting duct; NMG, $N$-methyl-D-glucamine; PD, potential difference.

J. Clin. Invest.

(c) The American Society for Clinical Investigation, Inc.

0021-9738/88/09/1067/08 $\$ 2.00$

Volume 82, September 1988, 1067-1074 be coupled to a basolateral $\mathrm{Na} / \mathrm{K}$-ATPase. Because of observations that amiloride, thiazide, and furosemide can inhibit sodium reabsorption by this segment in vivo, the mechanism of luminal sodium entry remains unclear $(2,4-6)$.

Aside from its ability to actively reabsorb sodium, the IMCD is of interest because this segment appears to be an epithelial site at which atrial natriuretic peptide (ANP) and other hormones regulate sodium excretion. In the case of ANP, studies in vivo from several laboratories have demonstrated that administration of ANP inhibits net sodium reabsorption in the IMCD (7-11). Although changes in peritubular factors may play a role in these responses (12), there is strong evidence that ANP alters net sodium transport in this segment by direct interaction with IMCD cells. Thus, several laboratories have demonstrated that ANP binds to specific cell-surface receptors for ANP (13) and that IMCD cells from multiple species respond to ANP with striking elevations in cGMP accumulation $(14,15)$. Further, we have previously shown that ANP inhibits transport-dependent oxygen consumption in IMCD cells and have provided evidence that ANP acts by inhibiting an amiloride-sensitive sodium entry pathway (16). We have further demonstrated that cGMP mediates these transport effects in IMCD cells (15). We have therefore examined more directly the mechanisms of sodium entry in IMCD cells and have determined the pathway regulated by ANP.

\section{Methods}

Cell preparations. Fresh suspensions of rabbit IMCD cells were prepared as previously described $(15,16)$. Briefly, rabbits were decapitated and exsanguinated and the kidneys were removed and perfused via the renal artery with a solution consisting of nonbicarbonate Ringer's, $\mathrm{pH}$ $7.40\left(\mathrm{NaCl}, 130 \mathrm{mM} ; \mathrm{KCl}, 5 \mathrm{mM} ; \mathrm{NaHPO}_{4}, 1 \mathrm{mM} ; \mathrm{CaCl}_{2}, 1 \mathrm{mM}\right.$; $\mathrm{MgSO}_{4}, 1 \mathrm{mM}$; Hepes-Tris, $10 \mathrm{mM}$ ) diluted 1:1 with Joklik's medium containing 10\% fetal bovine serum (Joklik's). The kidneys were perfused with iced medium until the effluent was clear of blood and the inner medullae were excised and placed in the Joklik's medium. The medullae were minced and subjected to dispersion in $0.2 \%$ collagenase for $90 \mathrm{~min}$ at $37^{\circ} \mathrm{C}$ in a shaking water bath. Two or three times during this incubation the tissue was aspirated through a wide-bore pipette to disrupt cell aggregates. The resulting mixed inner medullary cell suspension was fractionated in $16 \%$ Ficoll in nonbicarbonate Ringer's by centrifugation for $45 \mathrm{~min}$ at $2,300 \mathrm{~g}$ at $4^{\circ} \mathrm{C}$. Cells were used within $2 \mathrm{~h}$ of preparation and were kept on ice until study. The quality of cell preparations was monitored under phase-contrast microscopy on a daily basis. Viability was assessed by trypan blue exclusion. The resulting cell suspensions resemble closely IMCD cells in situ by light and electron microscopy and exhibit high glycolytic rates, low rates of basal oxygen consumption, cAMP accumulation in response to vasopressin, and cGMP accumulation in response to $\operatorname{ANP}(15,16)$.

Measurement of sodium uptake. Cells were preincubated for 60 min at $37^{\circ} \mathrm{C}$ in $\mathrm{KCl}$ Ringer's (nonbicarbonate Ringer's in which sodium salts were replaced with potassium salts on a mole for mole basis). Uptakes were started by adding $0.4 \mu \mathrm{Ci}^{22} \mathrm{Na}$ at a final sodium 
concentration of $5 \mathrm{mM}$ at $37^{\circ} \mathrm{C}$. Cells containing radioactivity were separated from isotope in free solution by centrifugation through oil. At the end of the uptake period, cells were diluted in triplicate at room temperature into $600 \mu \mathrm{l}$ of choline chloride solution (choline $\mathrm{Cl}, 130$ $\mathrm{mM}$; Hepes-Tris, $10 \mathrm{mM}$; LiCl, $1 \mathrm{mM}$; and amiloride, $0.1 \mathrm{mM}$ ) layered over $550 \mu \mathrm{l}$ of dioctylphthallate silicon oil, 1.75:1, followed immediately by centrifugation at $8,000 \mathrm{~g}$ for $20 \mathrm{~s}$. Under these conditions, IMCD cells were pelleted through the oil to the bottom of the tube while the aqueous layer remained on top; the oil layer retained little radioactivity. In control experiments, delay of centrifugation of up to $20 \mathrm{~s}$ after dilution of the cells into choline $\mathrm{Cl}$ solution did not alter radioactivity in the pellet. The aqueous layer was sampled for determination of specific activity of the isotope in the extracellular solution. The bottom of the microfuge tube was cut off and placed in a scintillation vial containing $0.5 \mathrm{ml} 6 \%$ perchloric acid, $1 \mathrm{mM}$ EDTA, and 4 $\mathrm{mM} \mathrm{CsCl}$. After vigorous mixing, the suspension was allowed to stand for $12 \mathrm{~h}$ at room temperature. The perchloric acid was then neutralized with $\mathrm{NaOH}$ and the radioactivity measured in Aquasol in a liquid scintillation counter. Protein content of cell suspensions was measured by Bio-Rad assay using bovine serum albumin as a standard.

Because the total radioactivity in the pellet is the sum of ${ }^{22} \mathrm{Na}$ in the extracellular space, bound to the cell surface, and transported into the cell, extracellular and bound radioactivity were measured by placing isotope and choline $\mathrm{Cl}$ solution above the oil mixture, adding cells, and immediately centrifuging (17). Subtraction of this zero time point radioactivity from the radioactivity obtained in each incubation revealed the portion of radioactive counts which represented uptake. This background represented $40-50 \%$ of total uptake under control conditions (see below) and was constant in multiple determinations on any given experimental day. Multiplication of the counts per minute of isotopic uptake by specific activity revealed the nanomoles of sodium entering the cells per unit time. Because $0.1 \mathrm{mM}$ ouabain increased uptake by $30-40 \%$, ouabain was used in all incubations; measurements of oxygen consumption in IMCD cells have demonstrated that this concentration of ouabain inhibits $\mathrm{Na} / \mathrm{K}$-ATPase maximally $(15,16)$. When cells were exposed to peptide hormones such as ANP, angiotensin II, or vasopressin, they were preincubated in the presence of peptide for 2 min prior to the uptake measurement. We have previously shown that ANP stimulates cGMP accumulation and inhibits oxygen consumption maximally at 2 min after its addition $(15,16)$.

Because the rate of sodium uptake was never linear at even the earliest timepoints (see, for-example, Fig. 1), initial rates were estimated when necessary utilizing a closed, two-compartment model (17): $\ln \left[1-\left(U_{t} / U_{\infty}\right)\right]=-k t$, where $U_{t}$ is the uptake of sodium at time, $t ; U_{\infty}$ is the uptake at infinite time, i.e., at equilibrium; and $k$ is the rate constant for entry of sodium into cells. Graphing the expression on the left against time yields a straight line of slope, $-k$.

Measurement of membrane potential. Fluorescence estimates of IMCD membrane potential (PD) were performed using the dye, DiS-C $\mathrm{C}_{3}-5$ (18) on an SLM-Aminco SPF-500 spectrofluorimeter (SLM Instruments, Urbana, IL) equipped with thermostatted cuvette holder, magnetic stirring, and an IBM-XT microcomputer. The basal fluorescence of $0.17 \mu \mathrm{M}$ dye in $3 \mathrm{ml}$ of buffer in quartz cuvettes previously equilibrated with this dye was determined at excitation wavelength 643 $\mathrm{nm}$, emission wavelength $666 \mathrm{~nm}$ (slits $2 \mathrm{~nm}$ ). In all solutions tested, including isotonic $\mathrm{NaCl}, \mathrm{KCl}$, and NMG-Cl Ringer's, resting fluorescence as well as the excitation and emission spectra of the dye were the same. IMCD cells were then added to the dye solution and the resulting quench determined. To perform standardizations, $3.33 \mu \mathrm{M}$ valinomycin was added followed by sequential additions of small volumes of 1 $\mathrm{M} \mathrm{KCl}$. Under the conditions used in this assay, cells and buffers in the absence of the dye gave no measurable fluorescence. Experiments ran 5 min or less; exposure of IMCD cells to $0.17 \mu \mathrm{M}$ DiS- $\mathrm{C}_{3}-5$ for $5 \mathrm{~min}$ at $37^{\circ} \mathrm{C}$ did not alter oxygen consumption and did not increase trypan blue uptake.

Measurement of intracellular $p H\left(p H_{i}\right)$. Cells were loaded in $\mathrm{KCl}$ Ringer's at $37^{\circ} \mathrm{C}$ with $2.5 \mu \mathrm{M} 2^{\prime}, 7^{\prime}$-bis-(2-carboxyethyl)-5 (and 6)-carboxyfluorescein, acetoxymethyl ester (BCECF-AM) for $45 \mathrm{~min}$ in the presence of $10 \mathrm{mM}$ glucose. Cells were then washed five to six times in buffer to remove extracellular BCECF. Intracellular $\mathrm{pH}$ was estimated by measuring the excitation ratio (502/430) of fluorescence of intracellular BCECF at emission wavelength $530 \mathrm{~nm}$. Cells preloaded with dye were suspended in $3 \mathrm{ml}$ of buffer at $37^{\circ} \mathrm{C}$ in the cuvette in the flurimeter and the fluorescence ratio recorded. At the end of the experiment, the extent of dye leakage was determined by removing the suspension, pelleting the cells, and measuring the fluorescence of the supernate at both excitation wavelengths. The fluorescence of the supernate was subtracted from that of the cell suspension to give the cellular fluorescence. The ratio of cellular fluorescence at excitation wavelengths 502 and $430 \mathrm{~nm}$ was then calculated. Standard curves relating cellular fluorescence to intracellular $\mathrm{pH}$ were performed daily using $1 \mu \mathrm{M}$ nigericin as previously described $(19,20)$.

Materials. ${ }^{22} \mathrm{Na}$ was obtained from Amersham Corp., Arlington Heights, Ill. Dioctylphthallate and silicone oil were obtained from Aldrich Chemical Co., Milwaukee, Wis. Di(S)- $\mathrm{C}_{3}-5$ and BCECF-AM were obtained from Molecular Probes, Junction City, OR. Collagenase was obtained from Worthington Biochemical Corp., Freehold, NJ; Joklik's minimal essential medium was obtained from Gibco, Grand Island, NY; and Ficoll was obtained from Pharmacia Fine Chemicals, Piscataway, NJ. 4-acetamido-4'-isothiocyanostilbene-2,2'-disulfonate (SITS) was obtained from Pierce Chemical Co., Rockford, IL and was kept frozen, in the dark and dissolved into stock solutions immediately before use. Bumetanide was a gift of Hoffmann-LaRoche Pharmaceuticals, Nutley, NJ; furosemide was a gift of Hoescht-Roussel Pharmaceuticals, Somerville, NJ. ANP $\left(\mathrm{ANP}_{1-28}\right)$ and atriopeptin I $\left(\mathrm{ANP}_{5-25}\right)$ were purchased from Penninsula Laboratories, Belmont, CA. Aquasol was obtained from New England Nuclear, Boston, MA. Bio-Rad protein assay kits were obtained from Bio-Rad Chemical Division, Richmond, CA. All other reagents were obtained from Sigma Chemical Co., St. Louis, MO and were of analytical grade.

Statistics. In all figures, a single $n$ represents the mean of determinations performed on a single cell preparation. Unless specified experimental results are given for the mean \pm SEM for at least three separate cell preparations. Protocols for which representative experiments are presented were also performed on at least three different cell preparations. Where appropriate results of different experimental groups are compared using paired $t$ tests; $P$ values $\leq 0.05$ were deemed significant.

\section{Results}

Fig. 1 presents an initial time course of sodium uptake in IMCD cells. As is evident, the rate of sodium uptake was never linear, even at the earliest timepoints. To obtain estimates of initial rates of sodium uptake, the data from the first $5 \mathrm{~min}$ of the timecourse were fitted to a two-compartment model as described above (see inset). The fitted curve is linear ( $r$ value $=0.979$ ), allowing the use of this method for comparing apparent initial rates of sodium uptake quantitatively between experimental groups.

To determine what mechanisms of sodium uptake might be present in freshly isolated IMCD cells, we examined sodium uptake at $5 \mathrm{~min}$ in the presence of inhibitors, all at $0.1 \mathrm{mM}$, of several different sodium transport processes. This relatively late timepoint was chosen because of the difficulty in obtaining results for sodium uptake which were sufficiently above background to be reliably analyzed when uptake was inhibited. As is evident in Fig. 2, hydrochlorthiazide, furosemide, and bumetanide were ineffective at inhibiting sodium uptake into IMCD cells. These results are entirely consistent with our previous observations that furosemide and hydrochlorthiazide did not inhibit oxygen consumption in IMCD cells and suggest that $\mathrm{Na} / \mathrm{Cl}$ cotransport and $\mathrm{Na} / \mathrm{K} / \mathrm{Cl}$ cotransport do not play a major role in $\mathrm{Na}$ uptake in these cells $(21,22)$. Addition of 


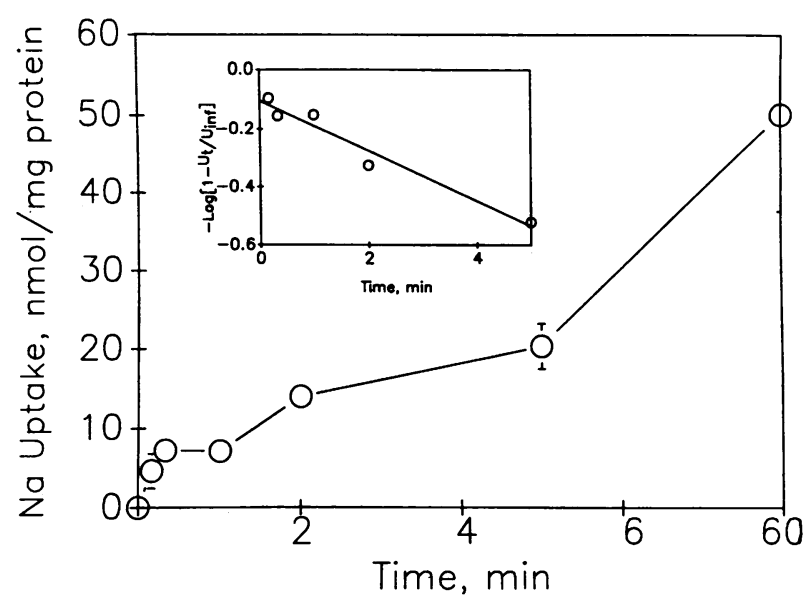

Figure 1. Time course of ${ }^{22} \mathrm{Na}$ uptake in IMCD cells. IMCD cells were preincubated in $\mathrm{KCl}$-Ringers for $60 \mathrm{~min}$ and then exposed to isotopic sodium at a final $[\mathrm{NaCl}]$ of $5 \mathrm{mM}$ for the indicated times before being separated from the aqueous medium by centrifugation through oil. Total radioactivity in the cell pellet, minus background represents uptake, in nanomoles per milligram of protein. Results represent the mean $\pm \mathrm{SE}$ of triplicate determinations on four to six cell preparations. (Inset) Data were redrawn using the two-compartment linearization described in Methods; $r=0.979$.

bicarbonate to the medium did not stimulate sodium uptake; in the presence of bicarbonate the stilbene anion transport inhibitor, SITS was without effect. These results indicate that $\mathrm{Na} / \mathrm{HCO}_{3}$ cotransport did not mediate a significant portion of sodium uptake in IMCD cells (23). By contrast, amiloride inhibited sodium uptake by $50 \%$. In several other experiments (not shown), amiloride inhibited uptake at 1 and 3 min as well. These results are in agreement with our previous findings that amiloride inhibits oxygen consumption in IMCD cells and "apical" sodium uptake in primary cultures of rabbit IMCD cells grown on filter bottom supports $(16,24)$.

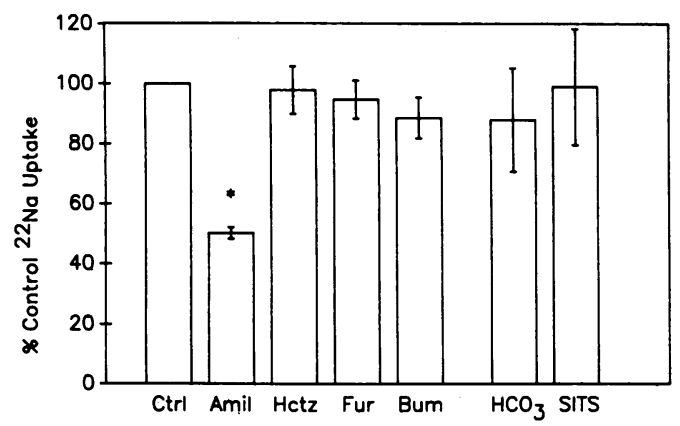

Figure 2. Effect of transport inhibitors on ${ }^{22} \mathrm{Na}$ uptake in IMCD cells. 5-min uptakes were performed as described in Fig. 1 in the presence of the following agents, added at the outset of the incubation: (Amil) $0.1 \mathrm{mM}$ amiloride; (Hctz) $0.1 \mathrm{mM}$ hydrochlorthiazide; (Fur) $0.1 \mathrm{mM}$ furosemide; (Bum) $0.1 \mathrm{mM}$ bumetanide; $\left(\mathrm{HCO}_{3}\right)$ cells preincubated and incubated in medium containing $25 \mathrm{mM} \mathrm{HCO}_{3}$ substituted mole-for-mole for $\mathrm{Cl}$; (SITS) $0.1 \mathrm{mM}$ 4-acetamido-4' isothiocyano-stilbene $2,2^{\prime}$ disulfonic acid in the presence of bicarbonate. Results are expressed as percent of the control value of sodium uptake obtained for a given experiment. Results represent the mean $\pm \mathrm{SE}$ of five or more experiments.
Inhibition of sodium entry into IMCD cells by amiloride suggested the presence of electrogenic sodium channels, $\mathrm{Na} / \mathrm{H}$ exchange, or both processes (25). Because of our earlier finding that IMCD oxygen consumption was inhibitable by amiloride levels in the submicromolar range (16), we explored the role of conductive sodium channels in sodium uptake by IMCD cells. The cyanine dye, $\mathrm{Di}(\mathrm{S})-\mathrm{C}_{3}-5$ was used to estimate membrane potential of IMCD cells in order to determine the effects of maneuvers designed to hyperpolarize the cells and to determine the effect of extracellular sodium on $\operatorname{PD}(18,26)$. Fig. 3 is a representative tracing depicting the effects of potassium gradients on fluorescence of the cyanine dye in the presence and absence of the potassium ionophore, valinomycin. In the upper tracing, basal fluorescence of $\mathrm{Di}(\mathrm{S})-\mathrm{C}_{3}-5$ was measured in $\mathrm{KCl}$ Ringer's followed by the addition of IMCD cells preincubated in the same medium. The negative deflection or quench represented accumulation of this cationic lipophilic molecule within the relatively anionic cytosol $(18,26)$. Addition of valinomycin $(V)$ to these cells resulted in increased fluorescence as extracellular potassium entered, thus depolarizing the cell membrane. In the bottom tracing, the dye signal was first obtained in NMG-Cl Ringer's. Addition of cells preincubated in $\mathrm{KCl}$-Ringer's led to a striking quench, resulting from the marked hyperpolarization brought on by efflux of potassium from the cells into a nearly potassium-free solution. Addition of valinomycin to these cells led to a further negative deflection as more potassium traveled down its concentration gradient from inside to outside the cells. Further addition of extracellular potassium increased fluorescence progressively, a consequence of reversal of the imposed gradient. Dilution of cells preloaded with potassium into $\mathrm{KCl}$ medium reduced fluorescence by $31.8 \pm 3.3 \%$, while dilution into N-methyl-Dglucamine (NMG)-Cl medium reduced fluorescence by 45.0 $\pm 5.1 \%(P<0.001, n=6)$.

Because dilution of potassium-loaded cells into NMG-Cl medium would be expected to reduce cell volume due to the relative impermeance of NMG, it is possible that the smaller cell volume may have altered the fluorescent properties of the cyanine dye. To address this issue, several control experiments were performed. First, the cells themselves in either NMG or

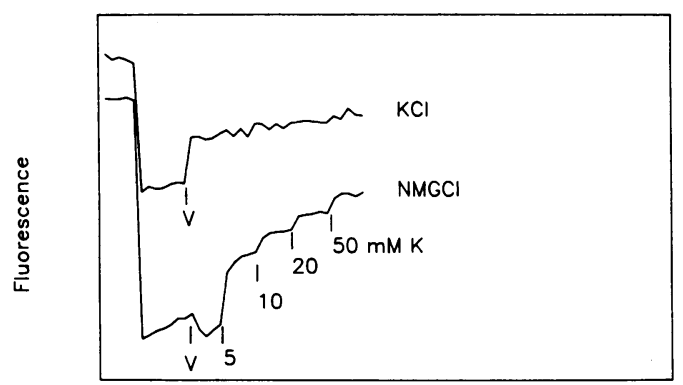

Figure 3. Effect of potassium gradients on DiS- $\mathrm{C}_{3}-(5)$ Fluorescence. Baseline fluorescence of DiS- $\mathrm{C}_{3}-(5)$ was measured in $\mathrm{KCl}$ (upper tracing) or $N$-methyl-D-glucamine-Cl (NMG-Cl, lower tracing) buffers. Cells preincubated in $\mathrm{KCl}$ buffer were then added and the resulting quench measured. $(V)$ Addition of the potassium ionophore, valinomycin. After addition of valinomycin to the cells diluted in NMG$\mathrm{Cl}$, extracellular potassium was increased in a stepwise manner to the values $5,10,20$, and $50 \mathrm{mM}$ during continuous monitoring of fluorescence. This figure is representative of similar experiments performed on three IMCD cell preparations. 
$\mathrm{K}$ media did not exhibit measurable fluorescence. In addition, the excitation spectrum of the dye remained the same under all experimental conditions; only proportional changes in fluorescence along the entire spectrum were observed with each experimental maneuver. Finally, osmotic shrinkage of IMCD cells with a $50 \%$ increase in extracellular osmolality (addition of $75 \mathrm{mM}$ NMG-Cl, changing osmolality from 300 to 450 mosmol) did not appreciably alter dye fluorescence. Thus, the changes in dye fluorescence depicted in Fig. 3 were not generated by changes in cell volume.

Graphing the change in fluorescence against the log of the potassium concentration (Fig. 4) gave a linear plot ( $r$ value 0.994), which was remarkably consistent from day to day. Over the range of potassium concentrations used, the calculated activity coefficient for potassium changed little; thus, the fluorescence intensity varied linearly with the logarithm of the potassium gradient across a membrane which was rendered highly conductive for potassium, indicating the validity of these measurements. The value of extracellular potassium at which the fluorescence after valinomycin reached the value observed before addition of ionophore was $\sim 3 \mathrm{mM}$. Assuming intracellular potassium concentrations ranging from 70 to $130 \mathrm{mM}$, cells preincubated in KCl-Ringer's and diluted into NMG-Cl Ringer's yield PDs between -85.6 and $-102.6 \mathrm{mV}$, while cells diluted into more $\mathrm{KCl}$-Ringer's yield membrane potentials between -57.0 and $-71.2 \mathrm{mV}$. Since we have not measured intracellular potassium concentration, these are only estimates of PD. However, these estimates of PD are reasonable when compared with the values obtained by microelectrode impalement of mammalian cortical and outer medullary collecting duct cells in a nonhyperpolarized state (27, 28). In addition, these results are similar to a membrane potential value of $-78 \mathrm{mV}$ obtained in rabbit IMCD cell suspensions in standard bicarbonate Ringer's using isotopically labeled triphenylmethylphosphonium ion (29).

Thus, as shown in Fig. 3, dilution of $\mathrm{KCl}$-loaded cells into NMG-Ringer's produces a striking hyperpolarization, especially when compared to similar cells diluted into $\mathrm{KCl}$ Ringer's. Fig. 5 demonstrates that this hyperpolarization protocol also produced striking stimulation of IMCD sodium uptake at all timepoints measured; the values of sodium uptake at equilibrium (60 min) were no different between control and hyperpolarized cells. The calculated rate constants for the control and hyperpolarized cells were $-0.051 \pm 0.015$ and

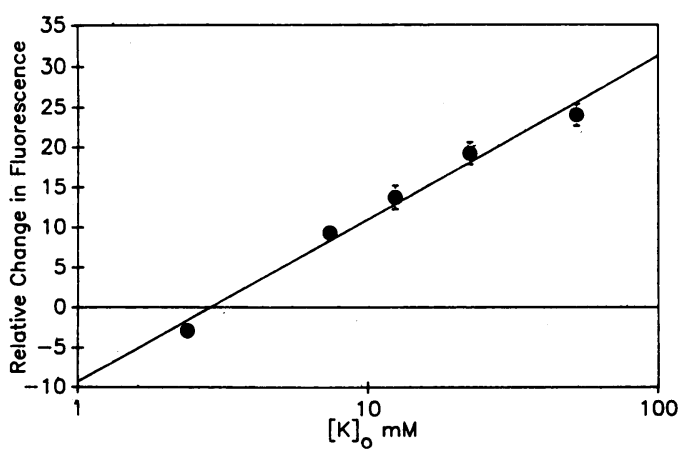

Figure 4. Relation of relative fluorescence to $\log [K]_{0}$. Data from three experiments similar to that of Fig. 3 plotted as relative fluorescence on ordinate vs. external potassium concentration on the abscissa.

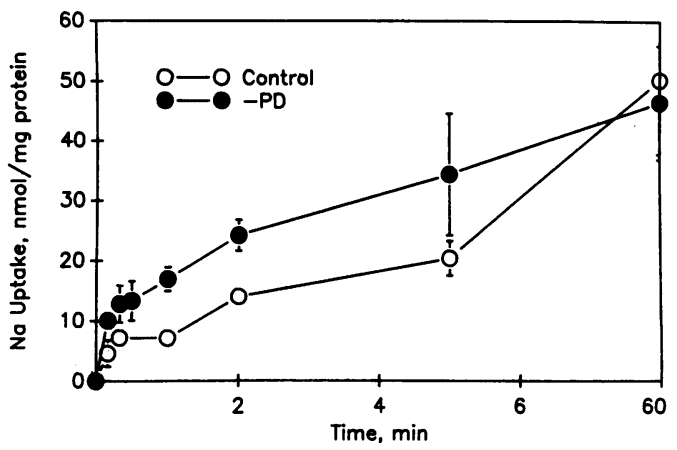

Figure 5. Effect of cell hyperpolarization on ${ }^{22} \mathrm{Na}$ uptake in IMCD Cells. Cells were preincubated in $\mathrm{KCl}$ Buffer and diluted 15-fold into $\mathrm{KCl}$ (Control) or NMG-Cl buffer (-PD) for assay of ${ }^{22} \mathrm{Na}$ uptake as described in Fig. 1. Control data is from Fig. 1.

$-0.207 \pm 0.056$, respectively with $r$ values averaging $0.96-0.97$ $(P<0.02, n=3)$. As shown in Figs. 6 and 7, both amiloride and ANP inhibited sodium uptake in control and hyperpolarized cells. In hyperpolarized cells, these agents were effective at all but the equilibrium timepoints (Fig. 6). Rate constants for uptake in hyperpolarized cells were, $-0.274 \pm 0.064$, $-0.0735 \pm 0.015$, and $-0.0948 \pm 0.028$ in cells treated with vehicle, amiloride, and ANP, respectively. Rate constants obtained for cells exposed to amiloride and ANP were significantly smaller than those obtained in cells exposed to vehicle $(P<0.02$ for both amiloride and ANP vs. vehicle, Bonferroni $t$ test, $n=4$ for each comparison; $r$ values ranging between 0.95 and $\mathbf{0 . 9 8}$ for all time course measurements). In control and hyperpolarized cells amiloride and ANP did not give additive inhibition of sodium uptake (Fig. 7), consistent with an action on a similar site. These results are in agreement with our previous finding that amiloride and ANP do not give additive inhibition of oxygen consumption in these cells (16), and indicate that amiloride and ANP inhibit conductive sodium entry via sodium channels in IMCD cells.

Because rat IMCD cells in primary culture have been reported to regulate intracellular $\mathrm{pH}$ via an electrogenic $\mathrm{H}^{+}$ATPase (29-31), it was possible that hyperpolarizing IMCD cells stimulated sodium uptake by acidifying the cells, leading

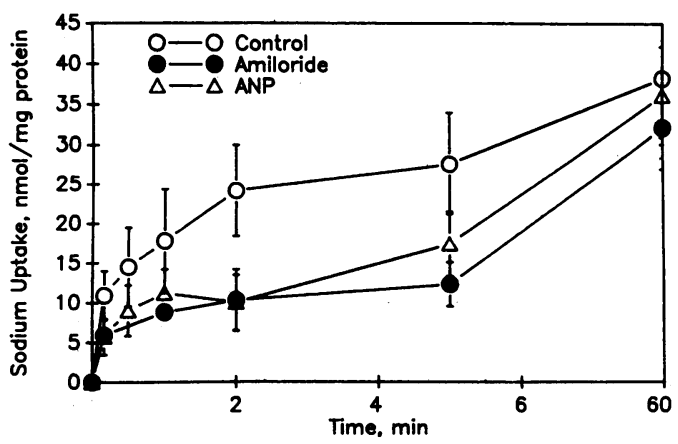

Figure 6. Effect of amiloride and ANP on ${ }^{22} \mathrm{Na}$ uptake in hyperpolarized IMCD cells. Sodium uptake was measured in hyperpolarized cells as described in Fig. 5. (Amiloride) Uptake in the presence of 0.1 $\mathrm{mM}$ amiloride (ANP) Cells were preincubated in $1 \mu \mathrm{M}$ ANP for 2 min the exposed to this level of peptide for the duration of the uptake assay. 


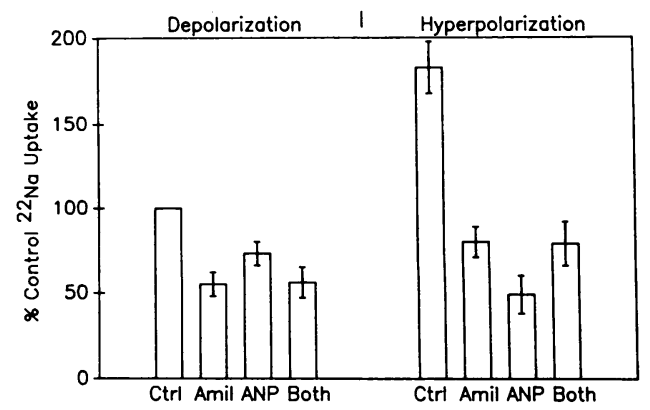

Figure 7. Effect of membrane potential, amiloride, and ANP on ${ }^{22} \mathrm{Na}$ uptake in IMCD cells. Results of 2-min timepoints from Fig. 5 and 6 plus uptakes performed in the presence of both amiloride (Amil) and ANP. Results are expressed as the percent of sodium uptake measured in the depolarization control $(\mathrm{Ctrl})$ condition on each experimental day. Uptakes in the presence of amiloride, ANP, or both agents were significantly reduced $(P<0.01, n=4-7$; Bonferroni $t$ test) when compared with their respective control (depolarization or hyperpolarization) uptakes.

to increased $\mathrm{Na} / \mathrm{H}$ exchange. Indeed, we have demonstrated the presence of amiloride-sensitive, electroneutral $\mathrm{Na} / \mathrm{H}$ exchange in IMCD cell suspensions (Kikeri and Zeidel, manuscript in preparation). We used two approaches to test this possibility: we measured intracellular $\mathrm{pH}$ in hyper and nonhyperpolarized cells, using protocols identical to those shown in Fig. 3, and we determined the effect of extracellular $\mathrm{Na}^{+}$on membrane potential. Intracellular $\mathrm{pH}$ of IMCD cells preincubated in KCl-Ringer's and diluted into more KCl-Ringer's was $7.22 \pm 0.01$, while $\mathrm{pH}_{\mathrm{i}}$ of cells from the same vial diluted into NMG-Cl Ringer's was 7.06 $\pm 0.03(n=3)$. While these pH values were significantly different, this level of acidification leads to barely perceptable increases in the rate of $\mathrm{Na} / \mathrm{H}$ exchange as measured by recovery of $\mathrm{pH}_{i}$, even in the presence of an outside to inside sodium gradient (Kikeri and Zeidel, unpublished observations). It is therefore unlikely that such a mild acidification would lead to a doubling of sodium uptake via $\mathrm{Na} / \mathrm{H}$ exchange, although it is possible that a small component of sodium uptake in the hyperpolarized cells is due to activation of $\mathrm{Na} / \mathrm{H}$ exchange by the acidification (see below).

The effect of extracellular sodium on PD is shown in Fig. 8. Cells were preincubated in $\mathrm{KCl}$-Ringer's and diluted into NMG-Cl Ringer's. After a new stable baseline had been reached (the starting point in the figure), $7.5 \mu \mathrm{l}$ of $2 \mathrm{M} \mathrm{NaCl}$ (final concentration, $5 \mathrm{mM}$ ) were added. The $\mathrm{NaCl}$ addition increased fluorescence by $6.7 \pm 0.4 \%$ consistent with a depolarization of PD of $\sim 24 \mathrm{mV}$. When $\mathrm{NaCl}$ was added to cells pretreated with $0.1 \mathrm{mM}$ amiloride, fluorescence rose by only $2.5 \pm 0.3 \%$, consistent with a depolarization of only $9.5 \mathrm{mV}$. The fluorescence values for the two groups were significantly different $(n=3 ; P<0.05)$, indicating that amiloride inhibited depolarization of IMCD cells in response to extracellular sodium. Addition of $5 \mathrm{mM} \mathrm{NMG-Cl}$ did not alter fluorescence (data not shown). Thus, addition of external sodium depolarizes IMCD cells via an amiloride-sensitive pathway. These results are in agreement with those reported previously in suspensions of rabbit IMCD cells by Prigent et al. (29). In those experiments, amiloride hyperpolarized the resting potential of the cells, suggesting that this agent inhibited the entry of positive charge into IMCD cells.

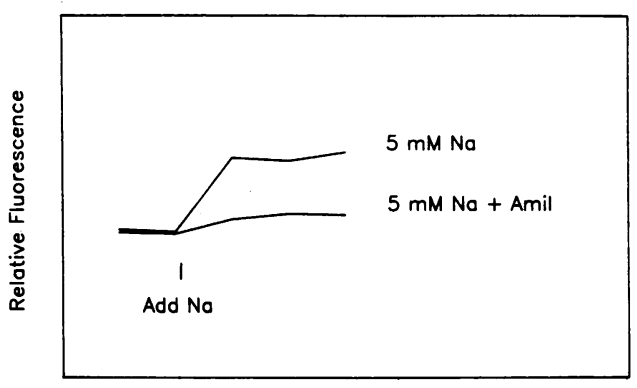

Figure 8. Effect of added extracellular sodium on membrane potential of hyperpolarized IMCD Cells. Cells were hyperpolarized as shown in Fig. 3 (preincubation in $\mathrm{KCl}$ buffer followed by dilution into NMG-Cl buffer). At the $A d d \mathrm{Na}$ point, $5 \mathrm{mM}$ extracellular $\mathrm{NaCl}$ was added in the presence ( $5 \mathrm{mMNa}+\mathrm{Amil}$ ) or absence of amiloride, and the fluorescence of the cyanine dye monitored. Total time of measurement was $4 \mathrm{~min}$. This tracing is representative of similar experiments performed in duplicate on three IMCD cell preparations.

Fig. 9 shows the effect of varying concentrations of ANP and amiloride on potential-stimulated sodium uptake in IMCD cells. Half-maximal inhibition of sodium entry with amiloride was observed at $\sim 3 \times 10^{-7} \mathrm{M}$, in close agreement with the effect of amiloride level on inhibition of oxygen consumption in these cells (16). As shown in Fig. 9, the inhibition of sodium uptake by amiloride continues to increase between $10^{-5}$ and $10^{-4} \mathrm{M}$; it is possible that this increment is due to inhibition of $\mathrm{Na} / \mathrm{H}$ exchange by amiloride in the hyperpolarized cells as discussed above. However, these results provide further evidence for a conductive sodium entry pathway in these cells, as the sensitivity of IMCD potential-driven sodium entry to amiloride matches closely the sensitivity of sodium channels in other epithelia to this agent (25). Half-maximal inhibition of potential-stimulated sodium entry occurred also at $10^{-10} \mathrm{M}$ ANP, in good agreement with previous binding, cGMP accumulation, and oxygen consumption data in these cells $(13,15,16)$.

Fig. 10 shows the effect of several agents on potentialdriven sodium uptake in IMCD cells. BroGMP and nitroprus-

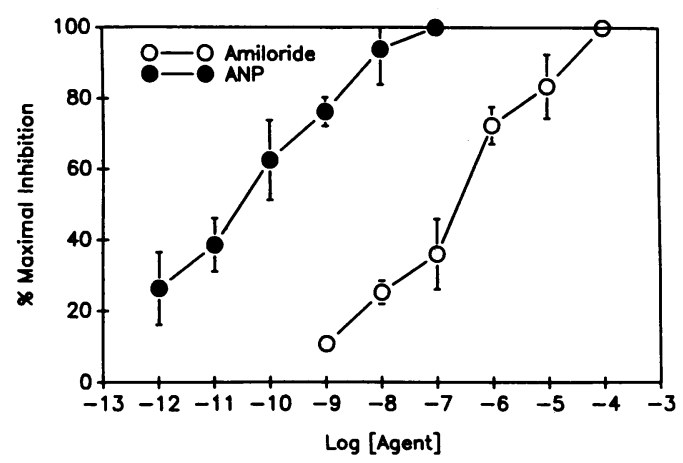

Figure 9. Effect of concentration of ANP or amiloride on percent inhibition of potential-driven sodium uptake in IMCD cells. Sodium uptakes were measured in the presence of the indicated concentration of $\mathrm{ANP}_{1-28}$ or amiloride. In the case of ANP, cells were pretreated with the indicated concentration of peptide for $2 \mathrm{~min}$ before the uptake measurement was initiated. Results are expressed as percent maximal inhibition of potential-driven sodium uptake in the absence of either agent. Maximal amiloride inhibition in these studies was $83.0 \pm 7.1 \%$; maximal ANP inhibition was $79.9 \pm 3.1 \%$. 


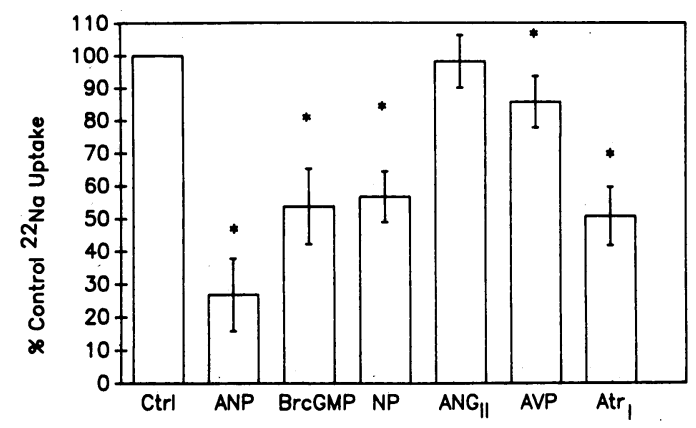

Figure 10. Effect of various agents on potential-driven sodium uptake in IMCD cells. Sodium uptake was measured in hyperpolarized cells in the presence of the agents shown and expressed as a percent of the control $(\mathrm{Ctrl})$ uptake for each experiment. $(A N P) 1 \mu \mathrm{M}$ $\mathrm{ANP}_{1-28}$; (BroGMP) $2 \mathrm{mM}$ 8-bromo-cyclic GMP; (NP) $10^{-5} \mathrm{M}$ sodium nitroprusside; $\left(A N G_{I I}\right) 1 \mu \mathrm{M}$ angiotensin II; $(A V P) 1 \mu \mathrm{M}$ arginine vasopressin; $\left(\right.$ Atr $\left._{I}\right) 1 \mu \mathrm{M}$ atriopeptin I $\left(\mathrm{ANP}_{5-25}\right)$. In the case of peptide hormones, cells were preincubated for $2 \mathrm{~min}$ before initiation of the uptake measurement. ${ }^{*} P<0.001$ compared with control, $n=6-9$ for each agent.

side, two agents which raise intracellular cGMP in these cells (15), inhibited sodium uptake. These results are in agreement with our previous finding that these agents inhibited oxygen consumption in IMCD cells (15). Vasopressin, which raises cAMP in these cells but does not alter oxygen consumption (M. L. Zeidel and P. Silva, unpublished observations), gave a slight, but statistically significant inhibition of potential-driven sodium uptake. $\mathrm{ANP}_{5-25}$, which inhibited oxýgen consumption in IMCD cells (16), also inhibited potential-driven sodium uptake. It is notable that this analogue of ANP binds poorly to IMCD ANP receptors and is a poor stimulant of cGMP accumulation in these cells.

\section{Discussion}

The IMCD is known to engage in active transport of sodium and to respond to a variety of hormones including ANP, vasopressin, kinins, and $\mathrm{PGE}_{2}(1,2,4,14,16,32-34)$. Because this segment is highly branched and difficult to dissect, in vitro microperfusion studies have only recently been performed with any success $(4,34)$. Accordingly, we have little or no information as to how sodium transport occurs, although it is highly likely that reabsorption of sodium occurs via a luminal entry step followed by active transport of sodium across the basolateral membrane via the $\mathrm{Na} / \mathrm{K}$-ATPase (2). We have therefore devoted some effort to determining the mechanisms of sodium entry in IMCD cells in suspension, since transport processes in these intact, freshly prepared cells would be expected to be similar to those observed in vivo. In addition, the fact that transport-dependent oxygen consumption in these cells is regulated by ANP, kinins, and $\operatorname{PGE}_{2}(16,32,33)$ makes these suspensions an excellent model system for examination of hormonal regulation of IMCD sodium transport.

We have demonstrated that measurable sodium uptake occurs via pathways which are not affected by agents which inhibit $\mathrm{Na} / \mathrm{Cl}$ cotransport (hydrochlorthiazide) or $\mathrm{Na} / \mathrm{K} / \mathrm{Cl}$ cotransport (furosemide and bumetanide) $(21,22)$. In the rat IMCD in vivo, hydrochlorthiazide and furosemide appear to inhibit net sodium reabsorption $(5,6)$. In the rat IMCD perfused in vitro, preliminary data indicate that basolateral furo- semide inhibits bath-to-lumen sodium flux, suggesting that a basolateral $\mathrm{Na} / \mathrm{K} / \mathrm{Cl}$ cotransporter mediates net sodium secretion in this segment, as it does in the shark rectal gland (35). In addition, furosemide inhibited oxygen consumption in rat IMCD cells in suspension, consistent with a $\mathrm{Na} / \mathrm{K} / \mathrm{Cl}$ cotransport pathway in this preparation (36). We have been unable to demonstrate sensitivity of rabbit IMCD cells to any loop diuretic, either with sodium uptake (present study) or oxygen consumption (16); it is likely that this apparent discrepancy relates to species differences.

The present results demonstrate the presence of a conductive sodium entry pathway in IMCD cells. Amiloride inhibits transport-dependent oxygen consumption in these cells, at concentrations suggestive of an epithelial sodium channel (16). In the present paper, we have measured sodium uptake directly. Sodium uptake was markedly stimulated by hyperpolarization of the cells. The stimulated uptake was completely inhibited by amiloride and amiloride was effective at concentrations of the drug which inhibit sodium channels in other epithelia (25). The hyperpolarization protocol, in which cells loaded with $\mathrm{KCl}$ were diluted into potassium-free medium, would be expected to hyperpolarize any cells with appreciable potassium permeability. To verify that hyperpolarization was achieved, fluorescence of the cyanine dye, $\mathrm{Di}(\mathrm{S})-\mathrm{C}_{3}-5$ was used as an index of membrane potential. In hyperpolarized cells, extracellular sodium depolarized the cells and this depolarization was inhibited by amiloride. Several lines of evidence support the presence of sodium channels in IMCD cells. In shrinking droplet experiments, Ullrich and Papavassiliou (2) showed that luminal amiloride inhibited volume reabsorption in the rat IMCD. In isolated rat inner medullary collecting ducts perfused in vitro, luminal amiloride abolished the slight lumen-negative potential, suggesting that this drug inhibited transport of positive charge from lumen to bath (37). In primary cultures of rat IMCD cells, a nonselective amiloride-sensitive cation channel has been demonstrated in cell-attached and detached patches (38). Finally, suspensions of rabbit IMCD cells were hyperpolarized in the presence of amiloride, suggesting that this agent acts in these cells to reduce the entry of positive charge (29). Thus, IMCD cells from both rat and rabbit exhibit amiloride-sensitive rheogenic sodium entry, indicating the presence of sodium channels.

The present conclusions depend, to some degree on the reliability of the cyanine fluorescence as an index of membrane potential. Although this method has been used extensively to monitor membrane potential in cell suspensions, concerns have been raised as to the effect of the dye on cell viability and the reliability of the method to measure PD (39). The concentration of dye used in these studies, $0.4 \mu \mathrm{M}$, is similar to that used with success by many other groups (18). In addition, exposure of the cells to the dye under conditions identical to those used for estimation of membrane potential did not alter trypan blue exclusion or oxygen consumption. Two further lines of evidence indicate that this dye provided a reliable index of IMCD cell PD. First; fluorescence varied linearly with the logarithm of external potassium concentration using cells permeabilized to potassium with valinomycin. Second, estimates of PD obtained using a reasonable range of values of intracellular potassium concentration gave reasonable values for $\mathrm{PD}$. Thus, our own results indicate that cyanine fluorescence provided a reliable index of IMCD membrane potential. 
An additional concern relates to the effect of changes in cell volume on sodium uptake. As noted above, dilution of IMCD cells into NMG-Cl medium would be expected to reduce cell volume because the intracellular ions, sodium and potassium are more permeant than extracellular NMG. The reduction in cell volume, by reducing intracellular water, would be expected to inhibit, and not stimulate sodium uptake. While it is possible that cell shrinkage would trigger volume regulatory mechanisms, the stimulation of sodium uptake in these measurements was blocked with amiloride, implicating activation of sodium channels or $\mathrm{Na} / \mathrm{H}$ exchange. Two lines of evidence indicate that $\mathrm{Na}$ channels, and not $\mathrm{Na} / \mathrm{H}$ exchange were activated. First, the uptake was sensitive to low concentrations of amiloride, and second, the NMG protocol resulted in minimal stimulation of $\mathrm{Na} / \mathrm{H}$ exchange as measured by proton transport.

There is now strong evidence that ANP causes natriuresis in part by interfering with normal sodium and volume reabsorption in the IMCD. Thus studies in vivo using microcatheterization and micropuncture techniques have demonstrated that ANP inhibits net sodium reabsorption in the IMCD (7-11). IMCD cells have specific ANP receptors of high affinity and respond to ANP with striking increases in cGMP accumulation (13-15). ANP inhibits transport-dependent oxygen consumption in rabbit IMCD cells (16). The response exhibited cell-type specificity, in that cells derived from rabbit outer medullary collecting duct and medullary thick ascending limb did not respond. Inhibition of oxygen consumption occurred at concentrations of ANP in the physiologic range and exhibited selectivity for peptide structure (16). The results of the present study confirm and extent these earlier findings, demonstrating that ANP at physiologic concentrations inhibits entry of sodium into IMCD cells via a rheogenic sodium channel. The recent demonstration of a similar inhibition of sodium uptake by the renal epithelial cell line, LLCPK $_{1}$, suggests that these cells mimic, in some ways, the medullary collecting duct $(40,41)$.

Recent studies of IMCD segments perfused in vitro confirm direct effects of ANP on IMCD transport. In rat IMCD, ANP reversed the direction of net sodium transport from net reabsorption to net secretion by inhibiting lumen to bath sodium flux and stimulating bath to lumen sodium flux. The inhibitory effect of ANP on lumen to bath sodium flux was particularly striking after this flux had been augmented by pretreatment with vasopressin (35). In addition, ANP inhibited vasopressin-stimulated osmotic water permeability in the IMCD (34).

In the setting of these results, the present demonstration that ANP inhibits conductive sodium entry in IMCD cells suggests a mechanism by which luminal sodium entry may be inhibited by this peptide in the IMCD in vivo. Inhibition of a luminal sodium channel explains, in part the natriuresis stimulated by ANP.

\section{Acknowledgments}

We thank Drs. Steven Hebert, Steven Gullans, and Barbara Ballermann for helpful discussions and suggestions throughout the course of this work. This work was supported by National Institutes of Health grants DK-38690, DK-18078 and DK-35930, and by a grant from Wyeth Laboratories. Dr. Zeidel is the recipient of a Veteran's Administration Career Development Award.

\section{References}

1. Jamison, R. L., H. Sonnenberg, and J. H. Stein. 1979. Questions and replies: role of the collecting tubule in fluid, sodium, and potassium balance. Am. J. Physiol. 237:F247-F261.

2. Ullrich, K. J., and F. Papavassiliou. 1979. Effect of adrenalectomy, low sodium diet, acetazolamide, bicarbonate-free solutions, and of amiloride. Pflügers Arch. Eur. J. Physiol. 379:49-52.

3. Cupples, W. A., and H. Sonnenberg. 1987. Load dependency of sodium chloride reabsorption by medullary collecting duct in rat. Am. J. Physiol. 253:F642-F648.

4. Rocha, A. S., and L. H. Kudo. 1982. Water, urea, sodium chloride, and potassium transport in the in vitro isolated perfused papillary collecting duct. Kidney Int. 22:473-484.

5. Wilson, D. R., U. Honrath, and H. Sonnenberg. 1983. Furosemide action on collecting ducts: effect of prostaglandin synthesis inhibition. Am. J. Physiol. 244:F666-F673.

6. Wilson, D. R., U. Honrath, and H. Sonnenberg. 1983. Thiazide diuretic effect on medullary collecting duct function in the rat. Kidney Int. 23:711-716.

7. Sonnenberg, H., W. A. Cupples, A. J. De Bold, and A. T. Veress. 1982. Intrarenal localization of the natriuretic effects of cardiac atrial extract. Can. J. Physiol. Pharmacol. 60:1149-1152.

8. Sonnenberg, H., U. Honrath, C. K. Chong, and D. R. Wilson. 1986. Atrial natriuretic factor inhibits sodium transport in medullary collecting duct. Am. J. Physiol. 250:F963-F966.

9. Fried, T. A., R. W. Osgood, and J. H. Stein. 1986. The effect of synthetic atrial natriuretic peptide on chloride handling in the rat. Proceedings of the First World Congress on Biologically Active Atrial Peptides. Vol. 1. Elsevier Science Publishing Co., Inc., New York, 117.

10. Van de Stolpe, A., and R. L. Jamison. 1987. Effect of atrial natriuretic peptide on sodium reabsorption in the rat collecting tubule. Proc. 10th Int. Cong. Nephrol. 10:222.

11. Briggs, J. P., H. Soejima, and J. Schnerrman. 1987. Effect of atrial natriuretic peptide on $\mathrm{Cl}$ absorption along papillary collecting ducts. Proc. 10th Int. Cong. Nephrol. 10:207.

12. Mendez, R. E., B. R. Dunn, J. L. Troy, and B. M. Brenner. 1986. Modulation of the natriuretic response to atrial natriuretic peptide by alterations in peritubular Starling forces in the rat. Circ. Res. 59:605-611.

13. Gunning, M., B. J. Ballermann, P. Silva, B. M. Brenner, and M. L. Zeidel. 1988. Characterization of atrial natriuretic peptide receptors in rabbit inner medullary collecting duct cells. Am. J. Physiol. In press.

14. Nonoguchi, H., M. A. Knepper, and V. C. Manganiello. 1987. Effects of atrial natriuretic factor on cyclic guanosine monophosphate and cyclic adenosine monophosphate accumulation in microdissected nephron segments from rats. J. Clin. Invest. 79:500-507.

15. Zeidel, M. L., P. Silva, B. M. Brenner, and J. L. Seifter. 1987. cGMP mediates effects of atrial peptides on medullary collecting duct cells. Am. J. Physiol. 252:F551-F559.

16. Zeidel, M. L., J. L. Seifter, S. Lear, B. M. Brenner, and P. Silva. 1986. Atrial peptides inhibit oxygen consumption in kidney medullary collecting duct cells. Am. J. Physiol. 251:F379-F383.

17. Soltoff, S. P., and L. J. Mandel. 1984. Active ion transport in the renal proximal tubule. I. Transport and metabolic studies. J. Gen. Physiol. 84:601-622.

18. Rink, T. J., C. Montecucco, T. R. Hesketh, and R. Y. Tsien. 1980. Lymphocyte membrane potential assessed with fluorescent probes. Biochim. Biophys. Acta. 595:15-30.

19. Zeidel, M. L., P. Silva, and J. L. Seifter. 1986. Intracellular pH regulation and proton transport by rabbit renal medullary collecting duct cells role of plasma membrane proton adenosine triphosphatase. J. Clin. Invest. 77:113-120.

20. Zeidel, M. L., P. Silva, and J. L. Seifter. 1986. Intracellular pH regulation in rabbit renal medullary collecting duct cells: Role of chloride-bicarbonate exchange. J. Clin. Invest. 77:1682-1688.

21. Ellison, D. H., H. Velazquez, and F. S. Wright. 1987. Thia- 
zide-sensitive sodium chloride cotransport in early distal tubule. Am. J. Physiol. 253:F546-F554.

22. O'Grady, S. M., H. C. Palfrey, and M. Field. 1987. Characteristics and functions of Na-K-Cl cotransport in epithelial tissues. Am. J. Physiol. 253:C177-C192.

23. Jentsch, T. J., H. Matthes, S. K. Keller, and M. Wiederholt. 1986. Electrical properties of sodium bicarbonate symport in kidney epithelial cells (BSC-1). Am. J. Physiol. 251:F954-F968.

24. Zeidel, M. L. 1986. Atrial natriuretic peptide and amiloride inhibit apical sodium fluxin cultured rabbit inner medullary collecting duct cells. Proceedings of the First World Congress on Biologically Active Atrial Peptides. Vol. 1. Elsevier Science Publishing Co., Inc., New York. 115-117.

25. Benos, D. 1982. Amiloride: a molecular probe of sodium transport in tissues and cells. Am. J. Physiol. 242:C131-C145.

26. Waggoner, A. 1976. Optical probes of membrane potential. $J$. Membr. Biol. 27:317-331.

27. Sansom, S. C., E. J. Weinman, and R. G. O’Neil. 1984. Microelectrode assessment of chloride-conductive properties of cortical collecting duct. Am. J. Physiol. 247:F291-F302.

28. Koeppen, B. M. 1985. Conductive properties of the rabbit outer medullary collecting duct: inner stripe. Am. J. Physiol. 248:F500F506.

29. Prigent, A., M. Bichara, and M. Paillard. 1985. Hydrogen transport in papillary collecting duct of rabbit kidney. Am. J. Physiol. 248:C241-C246.

30. Kleinman, J., S. Blumenthal, K. Reetz, E. J. Cragoee, N. Mandel, and J. Wiessner. 1986. $\mathrm{Na} / \mathrm{H}$ exchanger of medullary tubule cells in primary culture. Clin. Res. 34:601a. (Abstr.)

31. Wall, S., S. Maullem, and J. A. Kraut. 1988. Detection of a sodium hydrogen antiported in the cultured rat renal papillary collecting duct cell. Am. J. Physiol. In press.
32. Zeidel, M. L., J. L. Seifter, K. Jabs, and B. M. Brenner. 1987. Bradykinin inhibits transport-dependent oxygen consumption in rabbit inner medullary collecting duct cells. Kidney Int. 31:293.

33. Jabs, K., P. Silva, and M. L. Zeidel. 1988. Prostaglandin $E_{2}$ inhibits $\mathrm{Na} / \mathrm{K}-\mathrm{ATPase}$ in rabbit inner medullary collecting duct cells. Kidney Int. 33:268.

34. Nonoguchi, H., J. M. Sands, and M. A. Knepper. 1988. Atrial natriuretic factor inhibits vasopressin-stimulated osmotic water permeability in rat inner medullary collecting duct. Kidney Int. 33:278.

35. Rocha, A. S., and L. H. Kudo. 1988. Direct effect of atrial natriuretic factor on $\mathrm{Na}, \mathrm{Cl}$, and water transport in the papillary collecting duct. Proc. 10th Int. Congr. Nephrol. 10:218.

36. Grupp, C., E. Kinne-Saffran, J. B. Stokes, and R. Kinne. 1987. Evidence for a furosemide-sensitive Na-K-C-cotransport system in rat papillary collecting duct cells. Proc. 10th Int. Congr. Nephrol. 10:570:

37. Stanton, B. 1987. Cellular conductive properties of rat inner medullary collecting duct: effects of vasopressin. Proc. 10th Int. Congr. Nephrol. 10:580.

38. Light, D. B., F. V. McCann, T. M. Keller, and B. A. Stanton. 1988. Amiloride-sensitive cation channel in apical membrane of inner medullary collecting duct. Am. J. Physiol. In press.

39. Smith, T. C. 1982. The use of fluorescence dyes to measure membrane potentials. J. Cell. Physiol. 112:302-304.

40. Cantiello, H. F. and D. A. Ausiello. 1986. Atrial natriuretic factor and CGMP inhibit amiloride-sensitive $\mathrm{Na}$ transport in the cul-

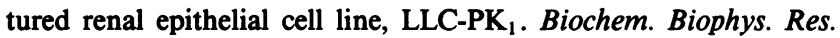
Commun. 134:852-860.

41. Goligorsky, M. S., R. L. Duncan, S. Westbrook, P. Reinach, and K. A. Hruska. 1987. Demonstration of a direct effect of atrial natriuretic factor on epithelium: study in cultured pig kidney cells. Mineral Electrolyte Metab. 13:51-56. 